\title{
Aiding the Self-Assembly of Supramolecular Polyoxometalates under Hydrothermal Conditions to give Precursors of Complex Functional Oxides
}

\author{
M. Sanchez-Sanchez, F. Girgsdies, M. Jastak, P. Kube, R. Schlögl, A. Trunschke* \\ Department of Inorganic Chemistry, Fritz-Haber-Institut der Max-Planck-Gesellschaft, \\ Faradayweg 4-6, 14195 Berlin, Germany, \\ * Corresponding author: e-mail annette.trunschke@,fhi-berlin.mpg.de,
}

Received: January 27, 2012; Revised: March 26, 2012; Published online: June 8, 2012

Keywords: hydrothermal synthesis; M1 phase; MoVTeNb oxides; polyoxometalates; Raman spectroscopy

The activation of small alkane molecules originating from natural gas or renewable resources will offer alternative pathways to functionalized hydrocarbons in a postpetroleum era. Crystalline or nano-crystalline molybdenum-vanadium based multi-metal oxides have been identified as versatile heterogeneous catalysts for selective oxidation of ethane, ${ }^{[1]}$ propane,${ }^{[2]}$ and propene. ${ }^{[3]}$

The crystal structures of these oxides show common structural attributes. In the framework of the tetragonal $\mathrm{M}_{5} \mathrm{O}_{14}$-type $(\mathrm{M}=\mathrm{Mo}, \mathrm{V}, \mathrm{W}, \mathrm{Ti}, \mathrm{Nb})$ structure (ICSD 27202), ${ }^{[4]}$ and in the orthorhombic M1 structure (ICSD 55097) of MoVTe(Sb)Nb(Ta) oxides, ${ }^{[5]}$ metal-oxide polyhedra are cross-linked in the crystallographic $a b$ plane by sharing corners or edges as shown in Schema 1. Needlelike nano-crystals growth along the crystallographic $c$ axis by linking corners of the polyhedra resulting in a short lattice constant $c$ at $0.4 \mathrm{~nm}$ and formation of channels with different sizes typical for oxidic bronzes. The structural motif $\left\{(\mathrm{M}) \mathrm{M}_{5}\right\},(\mathrm{M}=\mathrm{Mo}, \mathrm{V}, \mathrm{Nb})$, which is composed of a pentagonal bipyramidal $\mathrm{MO}_{7}$ unit that shares the five edges of the planar pentagon with five $\mathrm{MO}_{6}$ octahedra (Schema 1 ), is another common feature that is also known as a key constituent of larger structural aggregates appearing in the rich and beautiful chemistry of reduced molybdates in solutions. $^{[6]}$ Icosahedral molecular systems of the type $\left\{\left(\mathrm{Mo}^{\mathrm{VI}}\right) \mathrm{Mo}_{5}{ }^{\mathrm{VI}}\right\}_{12}(\text { linker })_{30}$, called Keplerates, have been considered as donor of the $\left\{(\mathrm{M}) \mathrm{M}_{5}\right\}$ building blocks in the $\mathrm{M}_{5} \mathrm{O}_{14}$ synthesis ${ }^{[7]}$ and the hydrothermal synthesis of $\mathrm{Mo}_{3} \mathrm{VO}_{\mathrm{x}}, \mathrm{MoVSb}$ and MoVTeNb mixed oxides with M1 structure. $^{[8]}$

The complexity of the M1 structure provides site isolation, as it is required for a high selectivity in oxidation reactions of $\mathrm{C} 3$ and $\mathrm{C} 2$ feedstock. ${ }^{[9]}$ Current synthetic approaches to phase-pure M1 suffer from insufficient repro

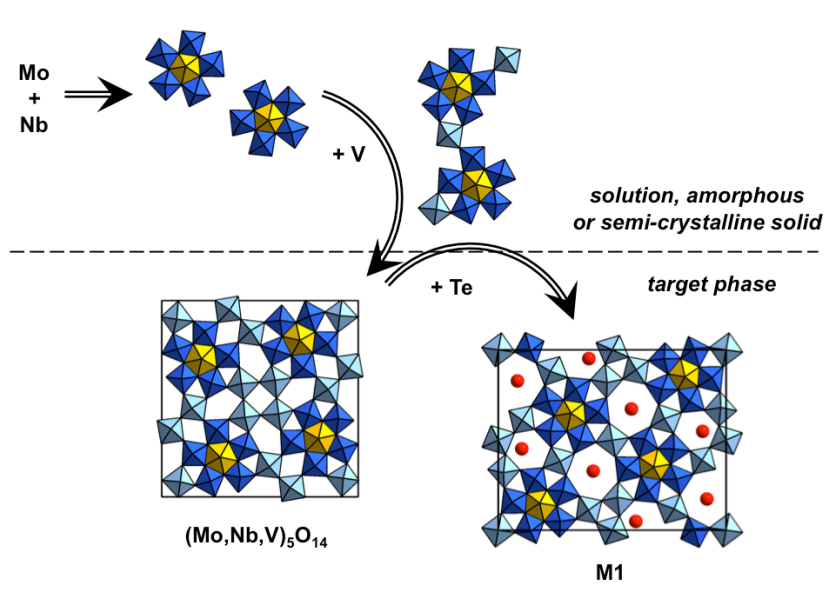

Scheme 1. Representation of the assembly of structural motives during formation of the target phase M1 and the by-product $(\mathrm{Mo}, \mathrm{Nb}, \mathrm{V})_{5} \mathrm{O}_{14}$.

ducibility, ${ }^{[10]}$ and apparently similar M1 catalysts may feature very different catalytic behaviour. ${ }^{[9,11]}$

Controlled synthesis of M1 with predictable surface properties requires deeper understanding of the inorganic reactions proceeding during assembly of structural building blocks and crystallization.

In this work, we have studied the formation of mixed MoVTeNb oxides under hydrothermal conditions by in-situ Raman spectroscopy. The spectroscopic information enabled the design of a new, accelerated and reproducible hydrothermal route towards precursors of phase-pure M1. Modular cross-linking of structural building blocks as outlined in Scheme 1 directs the synthesis towards the desired product avoiding the co-formation of unwanted phases. 


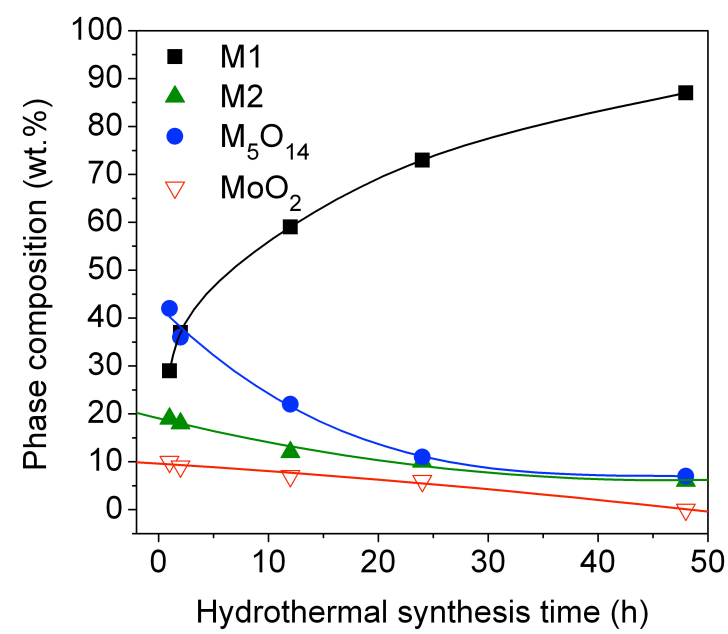

Figure 1. Evolution of phase composition of MoVTeNb oxides as a function of the hydrothermal reaction time at $\mathrm{T}=448 \mathrm{~K}, \mathrm{p}=14 \mathrm{bar}$.

In conventional hydrothermal recipes, the synthesis of MoVTeNb oxides is performed starting from suspensions of the oxides or metal salts in water and keeping the mixture for $48 \mathrm{~h}$ at $\mathrm{T}=448 \mathrm{~K}$ under autogeneous pressure (Fig. S1A). ${ }^{[2,8 d]}$ Fig. 1 shows the phase composition of hydrothermal reaction products after crystallization as a function of time. The chemical composition of complementary precipitates and mother liquors are presented in Figure $\mathrm{S} 2$ of the Supporting Information. Hydrothermal synthesis for short times yielded a mixture of $\mathrm{M}_{5} \mathrm{O}_{14}$-like oxide $(\mathrm{M}=$ $\mathrm{Mo}, \mathrm{V}, \mathrm{Nb}$ ), the pseudo-hexagonal M2 phase (ICSD $55098)^{[5 \mathrm{~b}]}$, the $\mathrm{M} 1$ phase, and a rutile-like phase $\mathrm{MO}_{2}$ $(\mathrm{M}=\mathrm{Mo}, \mathrm{V})$. With increasing reaction times, the fractions of $\mathrm{M}_{5} \mathrm{O}_{14}$ and $\mathrm{M} 2$ decrease while $\mathrm{M} 1$ becomes the main product.

The synthesis was monitored applying in-situ Raman spectroscopy. The assignment of the bands is discussed in detail in the Supporting Information. Mixing Mo and V salts at $313 \mathrm{~K}$ (Fig. 2) results in the formation of $\left\{\mathrm{Mo}_{72} \mathrm{~V}_{30}\right\}$ Keplerate ions $\left(868,945 \mathrm{~cm}^{-1}\right)^{[12]}$ as soon as the acidification of the solution by addition of vanadyl sulfate results in $\mathrm{pH}<4$ (Fig. S3). This observation is in perfect agreement with the recently reported spontaneous formation of $\left\{(\mathrm{Mo}) \mathrm{Mo}_{5}\right\}_{12}\left\{\mathrm{Mo}_{2}\right\}_{30}$-type Keplerates by addition of preformed $\left\{\mathrm{Mo}^{\mathrm{V}} \mathrm{O}\right\}^{2+}$ units to an acidified molybdate solution. ${ }^{[13]}$ These species contain the desired $\left\{(\mathrm{M}) \mathrm{M}_{5}\right\}$ structural motives that represent essential building blocks of the M1 structure, and V atoms are already situated in proper linking positions between these pentagonal units. The broad appearance between 1000 and $940 \mathrm{~cm}^{-}$ ${ }^{1}$ indicate the additional contribution of macroisopolyanions $\left[\mathrm{Mo}_{36} \mathrm{O}_{112}\right]^{8-}$ (Fig. S3). ${ }^{[14]}$ Subsequent addition of Te and heating to $353 \mathrm{~K}$ causes re-dissolution of the pre-formed $\left\{\mathrm{Mo}_{72} \mathrm{~V}_{30}\right\}$ Keplerate clusters and formation of heteropolymolybdate anions $\left[\left(\mathrm{TeO}_{3}\right)_{2} \mathrm{Mo}_{12} \mathrm{O}_{36}\right]^{4-}(773,786,808,967$ $\left.\mathrm{cm}^{-1}\right),{ }^{[15]}$ which are structurally closer related to the M2 phase and to other undesired crystalline phases like Te-
$\mathrm{Mo}_{5} \mathrm{O}_{16}$. Free telluric acid $\left(644 \mathrm{~cm}^{-1}\right),{ }^{[16]}$ Anderson-type heteropolyanions $\left[\mathrm{Te}(\mathrm{Mo}, \mathrm{V})_{6} \mathrm{O}_{24}\right]^{\mathrm{n}-}\left(952,1010 \mathrm{~cm}^{-1}\right),{ }^{[17]}$ and re-dissolved vanadium species $\left(975,1050 \mathrm{~cm}^{-1}\right)$ are also present. The final addition of $\mathrm{NH}_{4}\left[\mathrm{NbO}\left(\mathrm{C}_{2} \mathrm{O}_{4}\right)_{2}\right] \cdot \mathrm{xH}_{2} \mathrm{O}$ to the Mo-V-Te solution after cooling to $313 \mathrm{~K}$ did not change the Raman spectrum.

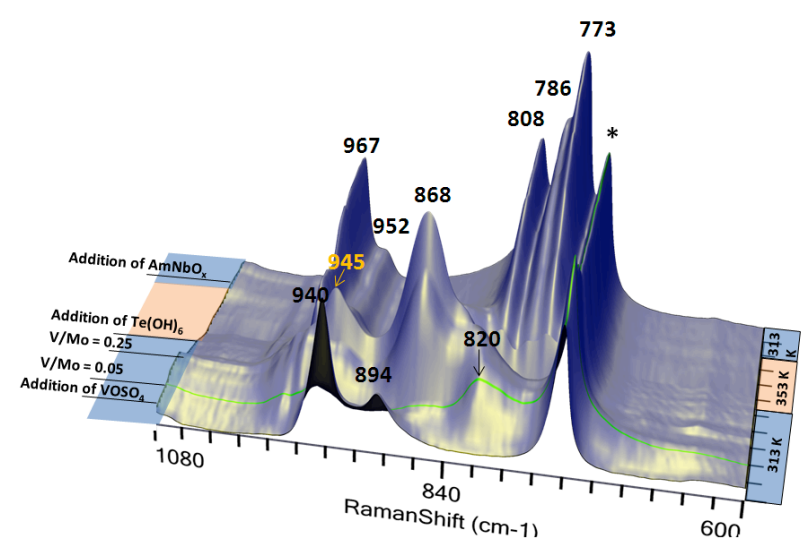

Figure 2. In-situ Raman spectra during preparation of the aqueous suspension before hydrothermal synthesis. For details see Supporting Information. Symbol (*) indicates a band of the sapphire window of the Raman probe.

During subsequent heating from $313 \mathrm{~K}$ to hydrothermal reaction temperature $448 \mathrm{~K}$ (Fig. 3), molybdotellurates are decomposed at $\mathrm{T}>393 \mathrm{~K}$ under intermediate formation of $\left[\mathrm{Mo}_{36} \mathrm{O}_{112}\right]^{8-}$ ions $\left(988,952\right.$ and $\left.912 \mathrm{~cm}^{-1}\right)$ leading to precipitation of nano-crystalline $\mathrm{M}_{5} \mathrm{O}_{14}$ $(\mathrm{M}=\mathrm{Mo}, \mathrm{V}, \mathrm{Nb})$ oxide $\left(835,930 \mathrm{~cm}^{-1}\right)$ at $\mathrm{T}>418 \mathrm{~K},{ }^{[18]}$ which is in good agreement with the predominance of this phase in the product obtained after short reaction times (Fig. 1). Since $\mathrm{Nb}$ is almost completely incorporated into the solid (Fig. S2), it is assumed that this element plays an important role in the formation of the $\mathrm{M}_{5} \mathrm{O}_{14}$ phase owing to its preference to occupy the $\mathrm{MO}_{7}$ pentagonal bipyramidal position in the $\left\{\left(\mathrm{M}_{5}\right) \mathrm{M}\right\}$ units. ${ }^{[5 b]}$

The spectral changes under isothermal conditions (Fig. S4) become more evident by analyzing the covariance of the observed Raman bands (Fig. 4). The broad contribution between 900 and $800 \mathrm{~cm}^{-1}$, which may indicate $\left\{(\mathrm{M}) \mathrm{M}_{5}\right\}$ units in nano-crystals of $\mathrm{M}_{5} \mathrm{O}_{14}$ and $\mathrm{M} 1$ (Figs. $\mathrm{S} 6-7),{ }^{[7 \mathrm{~b}]}$ and the band at $952 \mathrm{~cm}^{-1}$ for $\left[\mathrm{Mo}_{36} \mathrm{O}_{112}\right]^{8-}$ anions in solution, remained almost unchanged during the entire reaction. The macro-isopolyanions can be considered as species existing in equilibrium with the solid phase, being responsible for the substantial amount of Mo detected in solution after synthesis. The main changes are related to the growth of bands at 969, 931, 880,800, 726, and $323 \mathrm{~cm}^{-1}$. Since the resulting product is the precursor of a mixture of $\mathrm{M} 1, \mathrm{M} 2, \mathrm{M}_{5} \mathrm{O}_{14}$ and $\mathrm{MO}_{2}$ phases (Fig. 1), an unambiguous assignment of these bands is not possible. 


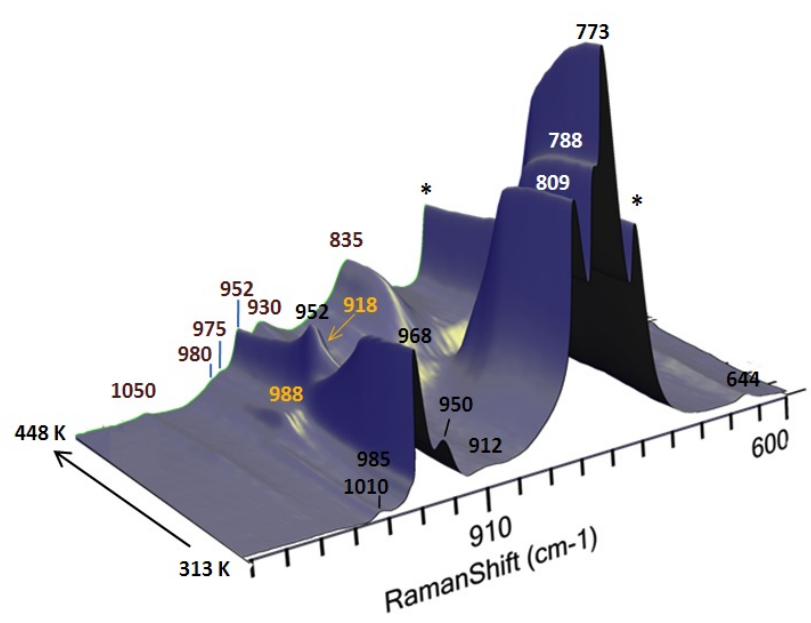

Figure 3. Raman spectra taken during heating from $313 \mathrm{~K}$ to 448 K.

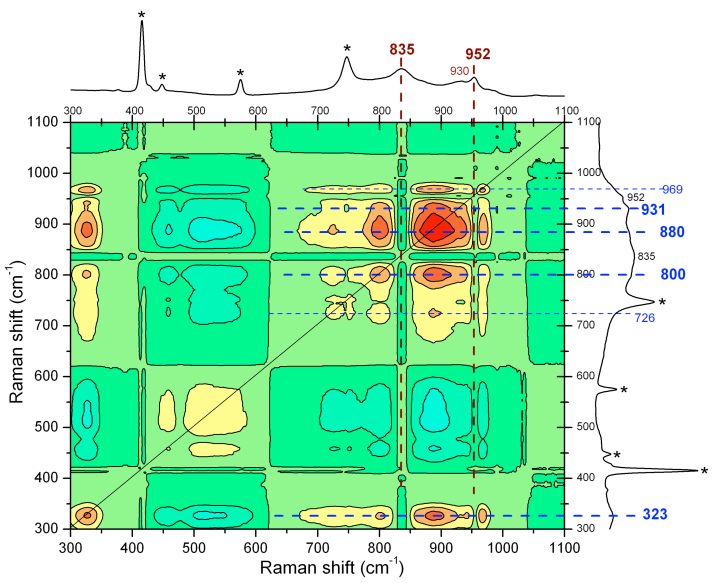

Figure 4. Covariance analysis of in-situ Raman bands measured during hydrothermal reaction at $448 \mathrm{~K}$. Initial spectrum shown on top; spectrum after $15 \mathrm{~h}$ on the right side.

Based on our knowledge acquired by in-situ Raman spectroscopy, we conceptually designed a novel, rational synthesis of phase-pure M1 MoVTeNb oxide by stepwise addition of $\mathrm{V}$ and Te under pressure (Fig. S1B). At first, a nano-crystalline oxide containing $\left\{(\mathrm{M}) \mathrm{M}_{5}\right\}$ units $\left(812 \mathrm{~cm}^{-1}\right)$ was formed by hydrothermal reaction of Mo and $\mathrm{Nb}$ precursors at $448 \mathrm{~K}$ (Fig. S5). At this point, an aqueous solution of $\mathrm{VOSO}_{4}$ is pumped into the autoclave with the aim to cross-link the pentagonal units with vanadium species, as depicted in Scheme 1. The subsequent introduction of Te as inorganic template is responsible for formation of nanocrystalline M1 (816, 870(sh), 919 and $\left.975 \mathrm{~cm}^{-1}\right)$ with enhanced precursor yield (Tab. S1),

which is of advantage in view of an improved control with respect to the final chemical composition of the solid. The isolated precipitate can be crystallized at $923 \mathrm{~K}$ in argon atmosphere resulting in phase-pure M1 (Figs. S6-7). The surface area of the new M1 is increased as a consequence of controlled initial precipitation of Mo species, which takes place through the decomposition of Mo oxalates (bands at 904 and $951 \mathrm{~cm}^{-1}$ in Fig S5). The retarded addition of Te avoids the formation of Te-Mo polyanions in solution, allowing precipitation of higher amount of product in shorter synthesis times at lower temperatures. The new M1 catalyst is characterized by distinguished selectivity to acrylic acid in selective oxidation of propane resulting in an increase in space time yield by a factor of five (Tab. $\mathrm{S} 1)$.

In summary, it is shown that the simultaneous study of multiple variables during formation of complex nanostructured solids in terms of inorganic systems chemistry ${ }^{[19]}$ offers a great potential in directing the properties of materials towards desired functionalities.

In-situ investigation of nano-particle synthesis provides insight into molecular processes of self-assembly and

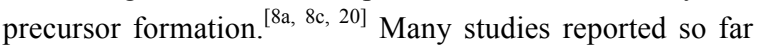
are focussed on binary and ternary systems. ${ }^{[20 c]}$ However, the complexity of materials required in the field of heterogeneous catalysis necessitates controlled synthesis strategies to create multi-component systems involving structures in the nano- and micro-meter length scale creating surface terminations unexpected from the bulk crystal structure. ${ }^{[21]}$ The present study of a practical system with substantial chemical complexity exemplifies a new paradigm of inorganic synthetic chemistry. Complex functional materials are assembled by generating sequences of reactions creating each a sub-unit of the target structure. This was enabled by combining the mild reaction environment of solvothermal synthesis with novel analytical capabilities that guide through in-situ monitoring of identified intermediates. It allows handling a wide spectrum of chemical elements. We describe here a platform procedure for a systemic synthesis approach aiming at generating complex functionality from structural inorganic concepts using a minimum of unit operations.

\section{Experimental Section}

The classical and step-wise synthesis procedures of MoVTeNb oxides are described in detail in the Supporting Information. In-situ Raman measurements were performed applying a Kaiser Optics Raman Spectrometer RXN1 equipped with a fiber-optic probe head, using a Laser wavelength of $785 \mathrm{~nm}$. Experimental details of characterization techniques and catalytic tests are summarized in the Supporting Information. 


\section{References}

[1] E. M. Thorsteinson, T. P. Wilson, F. G. Young, P. H. Kasai, Journal of Catalysis 1978, 52, 116.

[2] D. Vitry, Y. Morikawa, J. L. Dubois, W. Ueda, Topics in Catalysis 2003, 23, 47.

[3] J. B. Wagner, D. S. Su, S. A. Schunk, H. Hibst, J. Petzoldt, R. Schlögl, Journal of Catalysis 2004, 224, 28.

[4] L. Kihlborg, Acta Chem. Scand. 1969, 23, 1834.

[5] a)X. Li, D. Buttrey, D. Blom, T. Vogt, Topics in Catalysis 2011, 54, 614; b)P. DeSanto, Jr., D. J. Buttrey, R. K. Grasselli, C. G. Lugmair, A. F. Volpe, Jr., B. H. Toby, T. Vogt, Zeitschrift fuer Kristallographie 2004, 219, 152.

[6] a)A. Müller, C. Serain, Accounts of Chemical Research 2000, 33, 2; b)A. Müller, S. Polarz, S. K. Das, E. Krickemeyer, H. Bögge, M. Schmidtmann, B. Hauptfleisch, Angewandte Chemie International Edition 1999, 38, 3241; c)A. Müller, P. Kögerler, A. W. M. Dress, Coordination Chemistry Reviews 2001, 222, 193; d)A. Müller, P. Kogerler, C. Kuhlmann, Chemical Communications 1999, 1347; e)A. Müller, S. Roy, European Journal of Inorganic Chemistry 2005, 2005, 3561.

[7] a)S. Knobl, G. A. Zenkovets, G. N. Kryukova, R. I. Maksimovskaya, T. V. Larina, N. T. Vasenin, V. F. Anufrienko, D. Niemeyer, R. Schlögl, Physical Chemistry Chemical Physics 2003, 5, 5343; b)S. Knobl, G. A. Zenkovets, G. N. Kryukova, O. Ovsitser, D. Niemeyer, R. Schlögl, G. Mestl, Journal of Catalysis 2003, 215, 177.

[8] a)M. Sadakane, N. Watanabe, T. Katou, Y. Nodasaka, W. Ueda, Angewandte Chemie, International Edition 2007, 46, 1493; b)M. Sadakane, K. Yamagata, K. Kodato, K. Endo, K. Toriumi, Y. Ozawa, T. Ozeki, T. Nagai, Y. Matsui, N. Sakaguchi, W. D. Pyrz, D. J. Buttrey, D. A. Blom, T. Vogt, W. Ueda, Angewandte Chemie International Edition 2009, 48, 3782; c)R. Canioni, C. Marchal-Roch, N. LeclercLaronze, M. Haouas, F. Taulelle, J. Marrot, S. Paul, C. Lamonier, J.-F. Paul, S. Loridant, J.-M. M. Millet, E. Cadot, Chemical Communications 2011, 47, 6413; d)A. Celaya Sanfiz, T. W. Hansen, F. Girgsdies, O. Timpe, E. Rödel, T. Ressler, A. Trunschke, R. Schlögl, Topics in Catalysis 2008, $50,19$.

[9] A. Celaya Sanfiz, T. W. Hansen, D. Teschner, P. Schnörch, F. Girgsdies, A. Trunschke, R. Schlögl, M. H. Looi, S. B. A. Hamid, The Journal of Physical Chemistry C 2010, 114, 1912.
[10] A. Trunschke, in Nanostructured Catalysts: Selective Oxidation Reactions, 1 ed. (Eds.: C. Hess, R. Schlögl), RSC Nanoscience \& Nanotechnology, Cambridge, 2011, pp. 56.

[11] Y. V. Kolen'ko, W. Zhang, R. N. d'Alnoncourt, F. Girgsdies, T. W. Hansen, T. Wolfram, R. Schlögl, A. Trunschke, ChemCatChem 2011, 3, 1597.

[12] A. Müller, A. M. Todea, J. van Slageren, M. Dressel, H. Bögge, M. Schmidtmann, M. Luban, L. Engelhardt, M. Rusu, Angewandte Chemie International Edition 2005, 44, 3857.

[13] C. Schäffer, A. M. Todea, P. Gouzerh, A. Müller, Chemical Communications 2012, 48.

[14] a)K.-H. Tytko, B. Schönfeld, B. Buss, O. Glemser, Angewandte Chemie International Edition in English 1973, 12, 330; b)A. Müller, E. Krickemeyer, S. Dillinger, H. Bögge, W. Plass, A. Proust, L. Dloczik, C. Menke, J. Meyer, R. Rohlfing, Zeitschrift für anorganische und allgemeine Chemie 1994, 620, 599.

[15] S. Himeno, K.-i. Sano, H. Niiya, Y. Yamazaki, T. Ueda, T. Hori, Inorganica Chimica Acta 1998, 281, 214.

[16] J. Gupta, Nature 1937, 140, 685.

[17] a)I. L. Botto, C. I. Cabello, H. J. Thomas, Materials Chemistry and Physics 1997, 47, 37; b)Y. Sun, J. Liu, E. Wang, Inorganica Chimica Acta 1986, 117, 23.

[18] G. Mestl, C. Linsmeier, R. Gottschall, M. Dieterle, J. Find, D. Herein, J. Jäger, Y. Uchida, R. Schlögl, Journal of Molecular Catalysis A: Chemical 2000, 162, 463.

[19] R. F. Ludlow, S. Otto, Chemical Society Reviews 2008, 37, 101.

[20] a)A. M. Beale, G. Sankar, Chemistry of Materials 2002, 15, 146; b)C. Kongmark, V. Martis, A. Rubbens, C. Pirovano, A. Lofberg, G. Sankar, E. Bordes-Richard, R.-N. Vannier, W. Van Beek, Chemical Communications 2009, 4850; c)G. R. Patzke, Y. Zhou, R. Kontic, F. Conrad, Angewandte Chemie International Edition 2011, 50, 826; d)R. Kiebach, N. Pienack, W. Bensch, J.-D. Grunwaldt, A. Michailovski, A. Baiker, T. Fox, Y. Zhou, G. R. Patzke, Chemistry of Materials 2008, 20, 3022; e)R. I. Maksimovskaya, V. M. Bondareva, G. I. Aleshina, European Journal of Inorganic Chemistry 2008, 2008, 4906.

[21] W. Zhang, A. Trunschke, R. Schlögl, D. Su, Angewandte Chemie International Edition 2010, 49, 6084. 